\title{
Sulama Suyu Kalitesi ve Toprak Nem Düzeyinin Marulda Verim ve Kaliteye Etkisi
}

\author{
Engin YURTSEVEN ${ }^{1}$
}

\author{
Deniz Okan BOZKURT ${ }^{2}$
}

Geliş Tarihi : 30.04 .1997

\begin{abstract}
Ozzet: Bu çalışmada marul (Lactuca sativa cv. Tasna) bitkisinde 4 sulama suyu tuzluluğu $(0.25,2.0,4.0$ ve $6.0 \mathrm{dS} / \mathrm{m}$ ) ve 2 sodyum adsorbsiyon oranı $(0.30$ ve 5.0$)$ konularının verim ve kalite uzerine olan etkileri, 2 farklı toprak nem içeriği duzeyinde (kullanılabilir nemin \%75 ve \%25'i tuketildiğinde sulama) incelenmiștir. Çalışma tesadúf parsellerinde faktöriyel düzende 3 tekrarlamalı olarak, serada saksı denemesi biçiminde yưrütulmūştur. Sulama suyu tuzluluğu ve sodyumluluğundaki artışa bağlı olarak marul veriminde önemii azaimalar oluşmuştur. Bitki kuru madde miktarları azalırken, toplam kül miktarları artmıştır. Sulama suyu tuzluluğunun artișı ile tilineral madde içeriklerinin tümünde artma görülmüștür. Toprak nem içerikleri, tuzluluğun verim üzerine olan etkisi ile etkileşim göstermemiş, ancak toprakta nem düzeyinin yüksek tutulması verimin artmasina neden olmuştur.
\end{abstract}

Anahtar Kelimeler; Tuzluluk, marul, lactuca sativa, su kalitesi, verim, bitki kalitesi

\section{Effects of Irrigation Water Quality and Soil Moisture Content on Crop Yield and Qality of Lettuce}

\begin{abstract}
In this greenhouse study, the effect of 4 irrigation water salinity $(0.25,2.0,4.0$ and $6.0 \mathrm{dS} / \mathrm{m}), 2$ sodium $(S A R=0.30$ and 5.00 ) and 2 soil water content levels (irrigation when consumed $75 \%$ and $25 \%$ of available water) on the yield of lettuce (Lactuca sativa cV. Tasna) were investigated. For this purpose, factorial experiments in fully randomised design were conducted. As a result, increasing the irrigation water salinity and alkalinity reasoned to decrease the yield of lettuce and the amounts of plant biomass but to increase the total ash content and the mineral nutrient contents. Keeping the soil water content at $\% 75$ of available water level provoked to increase the yield of lettuce.
\end{abstract}

Key Words: Salinity, lettuce, lactuca sativa, water quality, yield, crop quality

Giriş

Sulamanın tarımsal açıdan önemi, son yıllara kadar çoklukla, fazla ayrıntıya girmeden yainızca sulama suyu miktarı ile açıklanmaktaydı. Ancak, son yıllardaki aşırı endüstriyel kullanım ve artan nüfus ile paralel olarak evsel kullanımın çoğalması, artık çok temiz su kaynaklarının varlığını tehdit etmekte ve genel olarak su kaynaklarının kalitelerinin, dış etkiler nedeniyle kötüleşmesine neden olmaktadır. Bu nedenle sulamada kullanılacak suların kalitelerinin hangi düzeye kadar kötüleşmesine ve yeterli verim ile tolere edebilir olduğuna araştırmalar yaparak karar verilmelidir. Suyun, içerisinde katı maddelerin eriyerek tuzluluğunun artması ile, kullanım için uygunluğu azalacaktır. Sulama suyu tuzluluğu, toprak çözeltisi ozmotik basıncını artırarak, bitkilerin kökleri ile suyu alımint zorlaştıracak, ya da içerisinde bulunan bazı toksik iyonlar nedeniyle bitkide zararlanmalara neden olacaktır. Bitkilerin tuzluluğa karşı olan tepkileri yani tuza dayanımları biribirinden farklıdır. Genel olarak sebzeler, tuza dayanımları diğer bitkilere göre daha düşuk olan bitki grubunu oluştururlar. Bu nedenle sebzeler sık ve iyi kaliteli sularla sulanmalıdırlar. Önemli bir besin maddesi olan marul (Lactuca sativa L.).

\footnotetext{
${ }^{1}$ Ankara Univ. Ziraat Fak. Tarımsal Yapılar ve Sulama Bölümü - Ankara

${ }^{2}$ Ziraat Yüksek Mühendisi
}

tuza orta hassas olan (Ayers ve Westcot 1989), ve toprak nem içeriğinin sık sulamalarla yüksek tutulmasının gerektiği bir kültür bitkisidir

Marul, yeşil taze sebze olarak vitamin ve mineral madde kaynağıdır. Turkiye'de toplam tarım alanlarının $\% 2.27$ 'sini oluşturan sebze üretim alanları içerisinde marul tarımı önemli bir yer tutmaktadır. Türkiye genelinde toplam sebze üretiminde yaklaşık olarak 135 bin ton marul üretimi gerçekleșmiş, bu miktar Ankara ve çevresinde ise yaklaşık 2460 ton olmuştur (Anonymous 1987).

Farklı marul çeşitleri ile yapılan denemelerde, tuzluluktaki artışın marul büyüklüklerinde azalmaya neden olduğu ve bitki ağırlığında, $E_{e}$ değerinin $4.4 \mathrm{dS} / \mathrm{m}$ alduğunda $\% 33,6 \mathrm{dS} / \mathrm{m}$ olduğunda ise $\% 50$ oranında bir azalma oluştuğu gözlemlenmiştir (Ayers ve ark.1951). Yapilan tuzluluk denemelerinde de benzer olarak verimde: Düşük tuzlulukta \%11, yüksek tuzlulukta ise $\% 26$ ya varan azalmalar belirlenmiş ve $\mathrm{NaHCO}_{3}$ tuzunun, 
diğer tuzlara göre, daha fazla verim azalmasına ve tepe yanıklığına yol açtığı belirtilmiştir (Sonneveld ve Den Ende 1975) Yapılan bir başka çalışmada ise, yaş ağırıkıarın 4.6 dS/m tuzluluk düzeyinde önemli bir azalma gösterdiği, azalmanın bu düzeyin üzerindeki her 1 dS $/ \mathrm{m}$ için $\% 45$ olduğu belirtilmiştir (Shannon ve ark. 1983). Marulda değişik tuzluluk dozeylerinin verim üzerine etkilerinin belirlenmesi amacıyla yapilan denemelerde, $E C_{1}=0,4.6$ ve $11 \mathrm{dS} / \mathrm{m}$ olan sulama sularının kullanılması lle oransal verimler sirasiyla $1.0,0.9$ ve 0.8 olmuştur (Dinar ve ark. 1986).

Bu çalişmada, insan beslenmesinde önemli bir besin kaynağı olan marul bitkisinde sulama suyu tuzluluğu ve sodyumluluğunun, toprak nem içerikleri ile ilişkili olarak, sera koşullarında, verim ve bitki mineral madde içeriğine olan etkileri incelenmiştir.

\section{Materyal ve Yöntem}

Çalışmaya ilişkin sera denemeleri, Toprak ve Gubre Araştırma Enstitüsū Müdürlüğa içerisinde yer alan beton zeminli, çelik profilli ve cam örtulü serada yürütülmüştür. Denemede kullanılan toprak materyali ise AnkaraYenimahalle ilçesine bağ/ Sarayköy dolaylarindan, üst 0$40 \mathrm{~cm}$ tarla toprağı kazılarak alınmıştır. Bu alanda yer alan topraklar azonal genç topraklardır ve bünyesi killi olan bu topraklar kuru iken sert olup nemli iken sıkı, yas iken yapışkan ve plastiktirler (Dizdar 1981). Denemelerde kullanilan sulama suyu Ankara şehir şebeke suyu olup elektriksel iletkenlik $\left(E C_{i}\right)$ deǧeri $0.25 \mathrm{dS} / \mathrm{m}$, sodyum adsorbsiyon oranı (SAR) ise 0.37 (me/l) $^{1 / 2}$ dolaylarindadır. Daha tuzlu sulama sularının elde edilmesinde sulama suyunun orijinal karakterini bozmamak amacıyla, erirlilikleri yüksek olan $\mathrm{NaHCO}_{3}$ $\mathrm{CaCl}_{2}$ ve $\mathrm{MgSO}_{4}$ tuzları kullanilmiştır (Yurtseven ve Sönmez 1996). Tuz eklenmesi aşamasında, toprak fiziksel özellikleri uzerine olan etkilerinin benzer olmasından ötürü $\mathrm{Ca} / \mathrm{Mg}$ oranı eklenen bazda $1 / 1$ olarak korunmuştur (Poonia ve Pal 1979). Çalışmada bitki materyali olarak Tasna çeșidi marul (Lactuca sativa) kullanilmıştır.

Tarladan alınan toprak materyali, sera içerisinde hava kurusu olarak kurutulduktan sonra $4 \mathrm{~mm}$ 'lik elekten geçiril-miş ve içerisine toprak verimlilik analizine göre belirlenen miktarda yanmış-elenmiş ahır gübresi eklenerek, $6.92 \mathrm{dm}^{3}$ hacmindeki plastik saksılara (No 9), olabildiğince doğal ha-cim ağırlığı korunacak biçimde yerleştirilmişlerdir. Hazırla-nan saksılar sera içerisinde
$0.80 \mathrm{~m}$ yüksekliğindeki masala-rın 0zerine, deneme düzenine uygun olarak yerleştirilmiştir.

Calıșa marul bitkisinde, farkli sulama suyu kalitesini içeren 4 tuzluluk $\left(T_{0}=0.25, T_{1}=2.0, T_{2}=4.0\right.$ ve $\mathrm{T}_{3}=6.0 \mathrm{dS} / \mathrm{m}$ ), 2 sodyumluluk (SAR değerleri olarak; $S_{0}=0.35$ ve $S_{1}=5.0$ ) düzeyi ve 2 toprak nem içeriği (kullanılabilir nem düzeyi $U_{0}=\% 75$ ve $U_{1}=\% 25$ däzeyine dơştăgünde sulama) konularının tesadüf parsellerinde faktöriyel dözende 3 tekrarlamalı olarak $(4 \times 2 \times 2 \times 3)$ ele alındığı, saksı denemeleri biçiminde yürütüımüştür. Sulama zamanının belirlenmesi için toprak nem dözeyleri gravimetrik yolla izlenmiştir. Saksılar periyodik olarak tartılarak nem içerikleri izlenmiş, $U_{0}$ ve $U_{1}$ konuları için sulama suyu miktarları ağırlık esasına göre belirlenmiştir.

Marul tohumları fide yetiştirmek amacıyla hazırlanan ve içerisinde $1 / 3 \mathrm{kum}, 1 / 3$ tarla toprağı ve $1 / 3$ yanmışelenmiş ahır gübresi karışımı bulunan ahşap kasalara ekilmişler ve fideler yaklaşık 3 hafta sonra, 3-4 yapraklı olduklarinda, deneme saksılarına dikilmişlerdir Marulun bitki besin maddeleri gereksinimini karşılayabilmek amacıyla Amonyum nitrat ve triple süper fosfat göbrelerinden verilmiştir. Fide dikiminden sonra ilk sulama şehir şebeke suyu kullanılarak yapılmış, daha sonra konulara geçilmiştir. Bitkiler yaklaşık 10 hafta sonra, baş gelişimini tamamlayıp tam olgunluğu aldıklarında, hepsi aynı zamanda hasat edilmişlerdir. Bitki vegetatif aksamı hemen toprak uzerinden kesilerek yapılan hasat sonrasında, bitki yaş ağırlıkları alınmıs ve en kısa surede kurutma firıninda $70^{\circ} \mathrm{C}$ 'de kurutulmuşlardır (Kacar 1972).

Toprak fiziksel analizlerinden tarla kapasitesi, devarnlı solma yüzdesi ve hacim ağırlığı analizleri ile toprak ve sulama suyunun tuzluluk analizleri (Anonymous 1954)'e göre, toprak bünyesi analizleri (Bouyoucos 1951)'e göre, bitkide kuru madde, toplam kül, ve mineral madde analizleri (Kacar 1972)'de verilen esaslara göre yapılmıştır. Denemeden elde edilen verilerin istatistik analizleri ise (Yurtsever 1984)'de verilen yöntemlere göre yapilmiştir.

\section{Bulgular ve Tartışma}

Marulda sulama suyu kalitesinin toprak nem içeriği ile ilişkili olarak verim ve kaliteye olan etkisinin belirlenmesi amacıyla yapılan bu çalışmada, kullanilan toprak materyaline ilişkin verimlilik ve fiziksel analiz bulguları Çizelge 1'de, toprak tuzluluk analizi bulguları ise Çizelge 2 'de verilmiştir.

Çizelge 1 - Toprak verimlilik ve fiziksel analiz bulguları

\begin{tabular}{|c|c|c|c|c|c|c|}
\hline $\begin{array}{c}\text { Su ile } \\
\text { doymuşluk } \\
(\%)\end{array}$ & $\begin{array}{c}\text { Toplam tuz } \\
\text { (\%) }\end{array}$ & $\begin{array}{c}\text { Doymuş } \\
\text { Toprakta } \\
\text { pH }\end{array}$ & $\begin{array}{c}\begin{array}{c}\text { Kireç } \\
\mathrm{CaCO}_{3}\end{array} \\
(\%)\end{array}$ & $\begin{array}{c}\text { Yarayışı। } \\
\text { Fosfor } \\
\mathrm{P}_{2} \mathrm{O}_{5} \\
\text { (Kg/da) }\end{array}$ & $\begin{array}{c}\text { Yarayışli } \\
\text { Potasyum } \\
\mathrm{K}_{2} \mathrm{O} \\
(\mathrm{Kg} / \mathrm{da})\end{array}$ & $\begin{array}{c}\begin{array}{c}\text { Organik } \\
\text { Madde }\end{array} \\
(\%)\end{array}$ \\
\hline 105 & 0.095 & 7.81 & 7.50 & 2.15 & 159.3 & 1.55 \\
\hline 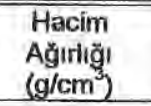 & $\begin{array}{c}\text { Tarla } \\
\text { Kapasitesi } \\
(\%)\end{array}$ & $\begin{array}{l}\text { Solma } \\
\text { Noktası } \\
(\%)\end{array}$ & $\begin{array}{l}\text { Kum } \\
\text { (\%) }\end{array}$ & $\begin{array}{l}\text { Silt } \\
\text { (\%) }\end{array}$ & $\begin{array}{l}\text { KiI } \\
\text { (\%) }\end{array}$ & $\begin{array}{l}\text { Banye } \\
\text { Sinifi }\end{array}$ \\
\hline 1.14 & 33.0 & 25.3 & 9.6 & 32.3 & 58.1 & c \\
\hline
\end{tabular}


Çizelge 2 - Toprak łuzluiuk analizi buiguları

\begin{tabular}{|c|c|c|c|c|c|c|c|c|}
\hline \multirow{2}{*}{$\begin{array}{c}\text { Saturasyon } \\
\%\end{array}$} & \multicolumn{2}{|c|}{$\mathrm{pH}$} & \multirow{2}{*}{$\begin{array}{c}E C \\
\langle\mathrm{dS} / \mathrm{m})\end{array}$} & \multicolumn{5}{|c|}{ Katyonlar (me/l) } \\
\hline & Çamurda & Ekstrakta & & $\mathrm{Na}^{+}$ & $\mathrm{K}^{+}$ & $\mathrm{Ca}^{++}$ & $\mathrm{Mg}^{+}$ & Toplam \\
\hline 108 & 7.82 & 7.95 & 0.91 & 2.73 & $0 . \overline{47}$ & 3.55 & 3.13 & 9.88 \\
\hline \multicolumn{5}{|c|}{ Anyoniar (me/l) } & \multirow{2}{*}{$\begin{array}{c}\text { Bor } \\
(\mathrm{ppm})\end{array}$} & \multirow{2}{*}{$\begin{array}{l}\text { ESP } \\
(\%)\end{array}$} & \multirow{2}{*}{\multicolumn{2}{|c|}{$\begin{array}{c}\text { CEC } \\
\text { (me/100g) }\end{array}$}} \\
\hline $\mathrm{CO}_{3}{ }^{\mathrm{I}}$ & $\mathrm{HCO}_{3}-$ & $\mathrm{Cl}$ & $\mathrm{SO}_{4}{ }^{2}$ & Toplam & & & & \\
\hline 0.35 & 3.75 & 4.13 & 1.82 & 10.05 & - & 2.52 & & 30.29 \\
\hline
\end{tabular}

Deneme toprağı kil bünyeli olup, yarayış|ı su tutma kapasitesi $26.3 \mathrm{~mm} / 30 \mathrm{~cm}$ dir. Toprak tuzluluğu 0.91 $\mathrm{dS} / \mathrm{m}$, değiş̧ebilir sodyum yüzdesi ise 2.52 olduğundan, tuzluluk ve sodyumluluk açisından sorunsuzdur:

Denemelerde kullanilan sulama sularinin analiz bulguları Çizelge $3^{\prime}$ de verilmiştir. Kontral konusu ( $T_{0} S_{0}$ ) suyu tuzluluğu $0.25 \mathrm{dS} / \mathrm{m}$ ve SAR değeri $0.37 \mathrm{dir}$. Bu suyun kalite sinıfi (Anonymous 1954)'e göre $C_{1} S_{1}$ olmaktadır ve her türlü kullanım için sorun yaratmayacak niteliktedir. Yine (Christiensen ve ark. 1977)'ye göre de $\% \mathrm{Na}, \mathrm{SAR}, \mathrm{RSC}, \mathrm{Cl}^{-}$ve Bor bakımından 1 . sinıf sulama suyu niteliğindedir

Kontrol konusuna çeşitli miktarlarda $\mathrm{NaHCO}_{3}$, $\mathrm{MgSO}_{4}$ ve $\mathrm{CaCl}_{2}$ tuzları katılarak oluşturulan diğer konuların elektriksel iletkenlik değerleri $T_{1}, T_{2}$ ve $T_{3}$ konulari için sırasıyla; $S_{0}$ düzeyinde $1.91,3.96$ ve 5.89 $\mathrm{dS} / \mathrm{m}, \mathrm{S}_{1}$ düzeyinde ise $1.96,4.00$ ve $5.98 \mathrm{dS} / \mathrm{m}$ olmuştur. Tuz katılarak oluşturulan sulama suları (C3) ve (C4) sinıflarına dahil olmaktadir (Anonymous, 1954). Suların SAR değerleri $S_{0}$ konuları için $0.37-0.58$ arasında, $S_{1}$ konuları için ise 4.53-5.08 arasında olmuştur. Bu değerlere göre kullanılan tüm sulama suları "düşük sodyumlu" sınıfına dahil olmaktadır.

Deneme konuları için elde edilen verim ve kalite değerlerinden bitki yaş ağırıkları, kuru madde miktarları, toplam kül ve mineral madde içeriklerine ilişkin bulgular Çizelge 4'de verilmiştir.
Elde edilen bulguların varyans analizleri incelendiğinde, deneme konuları olan sulama suyu tuzlulukları, SAR değerleri ve toprak nem içeriklerinin her üçü de, bitki verimleri üzerine istatistiksel olarak önemli düzeyde etki etmişlerdir. Bu etki tuzlulukta \%95, diğerlerinde ise $\% 99$ düzeyinde olmuştur. Konular arasındaki etkileşim ise önemsizdir. Bir başka deyişle konuların verim üzerine etkileri biribirlerinden bağımsız olmuştur. Verimlerin deneme konularına göre değişimi Şekil 1 ve 2 'de verilmiştir.

Verimdeki azalmalar tuzluluğun $T_{0}$ 'dan $T_{1}$ düzeyine yưkselmesi ile başlamış ancak $T_{1}, T_{2}$ ve $T_{3}$ konuları arasında istatistiksel açıdan bir farklılık görülmemiştir (Çizelge 5). Yani tuzluluğun 2 dS/m'ye yükselmesi verimde azalmayı başlatmış ancak $6 \mathrm{dS} / \mathrm{m}$ düzeyine kadar görülen azalma oranlarının tümü aynı grupta yer almıştır. Yine gelişme dönemi içerisinde toprak nem içeriklerinin farklı olarak korunması, bitki verimini etkilemiştir. Sulamalrın kullanılabilir nem düzeyinin sürekli olarak \%75 düzeyine azaldığında yapıldığı konuda $\left(U_{0}\right)$ ortalama verim $142.65 \mathrm{~g} / \mathrm{saks}$ iken, $\% 25$ düzeyine azaldığında yapıldığı $U_{1}$ konusunda ortalama 119.07 $\mathrm{g} / \mathrm{saksı}$ olmuştur. Ancak sonuçlar incelendiğinde tuzluluk ile toprak nem içeriği etkileşiminin önemsiz olduğu görülmüștür. Bir başka deyişle, sulama suyu tuzlulukları nedeniyle oluşan verim azalmaları, toprak nem içeriği düzeylerinden bağımsız olarak meydana gelmiştir.

Çizelge 3- Sulama suyu kalite analizi bulguları

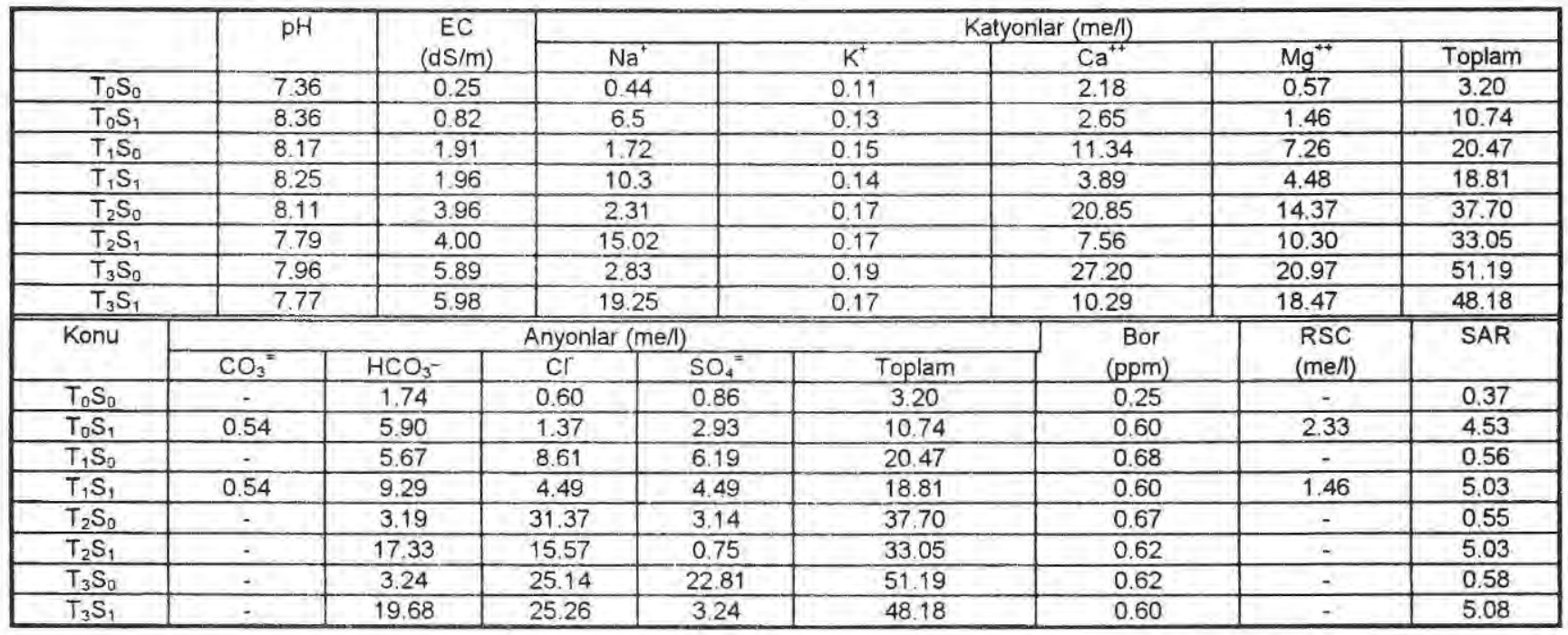


Çizelge 4 - Bitki verimleri ve kuru ağırikları, toplam kal ve mineral madde içerikteri (Tekrarlamalarin ortalamalan olarak)

\begin{tabular}{|c|c|c|c|c|c|c|c|}
\hline \multirow[t]{2}{*}{ Konu } & \multirow{2}{*}{$\begin{array}{c}\text { Verim } \\
\text { (g/saksi) }\end{array}$} & \multirow{2}{*}{$\begin{array}{c}\text { Kuru madde } \\
(\%)\end{array}$} & \multirow{2}{*}{$\begin{array}{c}\text { Toplam kül } \\
(\%)\end{array}$} & \multicolumn{4}{|c|}{ Mineral madde (ppm) } \\
\hline & & & & $\mathrm{Na}^{+}$ & $\mathrm{K}^{+}$ & $\mathrm{Ca}^{1+}$ & $\mathrm{Mg}^{++}$ \\
\hline $\mathrm{T}_{0} \mathrm{~S}_{0} \mathrm{U}_{0}$ & 158.17 & 6.15 & 19.35 & 4320 & 96339 & 15892 & 4085 \\
\hline $\mathrm{T}_{0} \mathrm{~S}_{0} \mathrm{U}_{1}$ & 150.20 & 6.21 & 20.82 & 4084 & 91597 & 14836 & 4156 \\
\hline $\mathrm{T}_{0} \mathrm{~S}_{1} \mathrm{U}_{0}$ & 151.83 & 6.73 & 17.73 & 4878 & 98445 & 13845 & 4098 \\
\hline $\mathrm{T}_{0} \mathrm{~S}_{1} \mathrm{U}_{1}$ & 127.77 & 5.63 & 21.21 & 4712 & 97462 & 15437 & 4374 \\
\hline $\mathrm{T}_{1} \mathrm{~S}_{0} \mathrm{U}_{0}$ & 145.17 & 6.71 & 17.51 & 4263 & 92832 & 15398 & 4440 \\
\hline $\mathrm{T}_{1} \mathrm{~S}_{0} \mathrm{U}_{1}$ & 128.50 & 7.03 & 18.52 & 3996 & 94568 & 15550 & 4606 \\
\hline$T_{1} S_{1} U_{0}$ & 133.50 & 6.16 & 18.91 & 5260 & 94306 & 13164 & 4155 \\
\hline $\mathrm{T}_{1} \mathrm{~S}_{1} \mathrm{U}_{1}$ & 97.70 & 6.45 & 19.23 & 5221 & 104157 & 13349 & 4191 \\
\hline $\mathrm{T}_{2} \mathrm{~S}_{0} \mathrm{U}_{0}$ & 144.67 & 6.66 & 18.17 & 3692 & 86513 & 15139 & 4871 \\
\hline $\mathrm{T}_{2} \mathrm{~S}_{0} \mathrm{U}_{1}$ & 124.57 & 6.59 & 20.13 & 4115 & 101277 & 14148 & 4563 \\
\hline $\mathrm{T}_{2} \mathrm{~S}_{1} \mathrm{U}_{3}$ & 143.33 & 6.86 & 19.14 & 5528 & 91517 & 14120 & 4390 \\
\hline $\mathrm{T}_{2} \mathrm{~S}_{1} \mathrm{U}_{1}$ & 99.43 & 7.37 & 18.11 & 5466 & 100857 & 14640 & 4233 \\
\hline $\mathrm{T}_{3} \mathrm{~S}_{0} \mathrm{U}_{0}$ & 148.53 & 6.46 & 19.05 & 3694 & 92215 & 12845 & 4194 \\
\hline $\mathrm{T}_{3} \mathrm{~S}_{0} \mathrm{U}_{1}$ & 121.67 & 6.58 & 19.22 & 3810 & 104741 & 15986 & 5259 \\
\hline $\mathrm{T}_{3} \mathrm{~S}_{1} \mathrm{U}_{0}$ & 116.00 & 6.47 & 19.25 & 5779 & 89166 & 14447 & 4785 \\
\hline$T_{3} S_{1} U_{1}$ & 102.80 & 7.12 & 19.91 & 5618 & 100214 & 14592 & 4643 \\
\hline
\end{tabular}

Çizelge 5 - Ortalama bitki verimleri için Duncan testi

\begin{tabular}{|c|c|c|}
\hline Tuzluluk Duzeyi & $\begin{array}{c}\text { Ortalama verim } \\
(\mathrm{g} / \text { saksi) }\end{array}$ & Duncan gruplandirması \\
\hline$T_{0}$ & 147.0 & $\mathrm{~A}$ \\
\hline$T_{2}$ & 128.0 & $\mathrm{~B}$ \\
\hline$T_{1}$ & 126.2 & $\mathrm{~B}$ \\
\hline$T_{3}$ & 122.2 & $\mathrm{~B}$ \\
\hline
\end{tabular}

Bitki kuru madde miktarları varyans analizi sonuçlarına göre, kuru madde miktarları üzerine önemli etki yapan konuların SAR ve toprak nem içerikleri olduğu belirlenmiştir. Sulama suyu tuzlulukları ve deneme konularının etkileşimleri ise istatistiksel olarak önemli bir etki oluşturmamıştır.

Bitki kuru madde miktarları, sulama suyu SAR değerinin $S_{0}$ dan $S_{1}$ düzeyine değişmesi ile ortalama $\% 6.55$ 'den $\% 6.60$ düzeyine, toprak nem içeriklerinin $U_{0}$ 'dan $U_{1}$ düzeyine olan değişimi sonucunda ise $\% 6.53$ 'den \%6.62 düzeyine artmıştır (Şekil 3 ve 4).

Marulda tuzluluğun bitki kalitesi üzerine olan etkilerinin belirlenebilmesi amacıyla, bitki örneklerinde toplam kül ve mineral madde $\left(\mathrm{Na}^{+}, \mathrm{K}^{+}, \mathrm{Ca}^{++}\right.$ve $\mathrm{Mg}^{++}$) analizleri yapılmıştır. Analiz bulguları Çizelge 4'de görülmektedir.

Toplam kül miktarları üzerine yalnızca toprak nem içeriği konulan \%95 däzeyinde önemli bir etki oluşturmuş. buna karşın tuzluluk ve SAR düzeyleri önemli bir etki yaratmamıştır. Konular arasındaki etkileşim de önemsizdir.
Bitki örneklerindeki $\mathrm{Na}^{+}$miktarları incelendiğinde, $\mathrm{Na}^{+}$iyonu tüm konularda 3492 ila 5854 ppm arasında bulunmuş, SAR ve ECixSAR etkileşimi $\% 99$ düzeyinde önemli çıkmıştır. Bir başka deyişle, $\mathrm{Na}^{+}$miktarı tuzluluk ve SAR düzeylerine bağlı olarak değișiklik göstermiştir. Bitki $\mathrm{K}^{+}$içerikleri deneme konulan için herhangi önemli bir değişim göstermemiştir. $\mathrm{Ca}^{++}$miktarlarının örneklerdeki miktarları 12030 ila 16871 ppm arasında olmuş ve SAR ile $E C_{i} x S A R$ etkileşimi önemli bulunmuştur. Burada sodyumluluğun etkisi \%99, EC $C_{i} x S A R$ etkileşiminin etkisi ise $\% 95$ düzeyinde önemlidir. Sulama suyu tuzluluğunun artması ile ve SAR düzeyinin $S_{0}$ dan $S_{1}$ däzeyine değişmesi ile bitkide $\mathrm{Ca}^{++}$içeriği azalmaktadır. Bir başka deyişle $\mathrm{Na}^{+}$düzeyinin artması ile $\mathrm{Ca}^{+*}$ alımı azalmaktadır. $\mathrm{Mg}^{++}$içerikleri ise örneklerde 3678 ila 5660 Yppm arasında bulunmuş ve $\mathrm{EC}_{\mathbf{i}}$ değerlerinin etkisi \%99, SAR ile EC $x$ XSARXNem etkileşiminin etkisi \%95 düzeyinde önemli olmuştur.

Marulda toplam kül ile $\mathrm{Na}^{+}, \mathrm{Ca}^{++}$ve $\mathrm{Mg}^{++}$ içeriklerinin değişimleri Şekil $5,6,7$ ve 8 'de gösterilmiştir. 


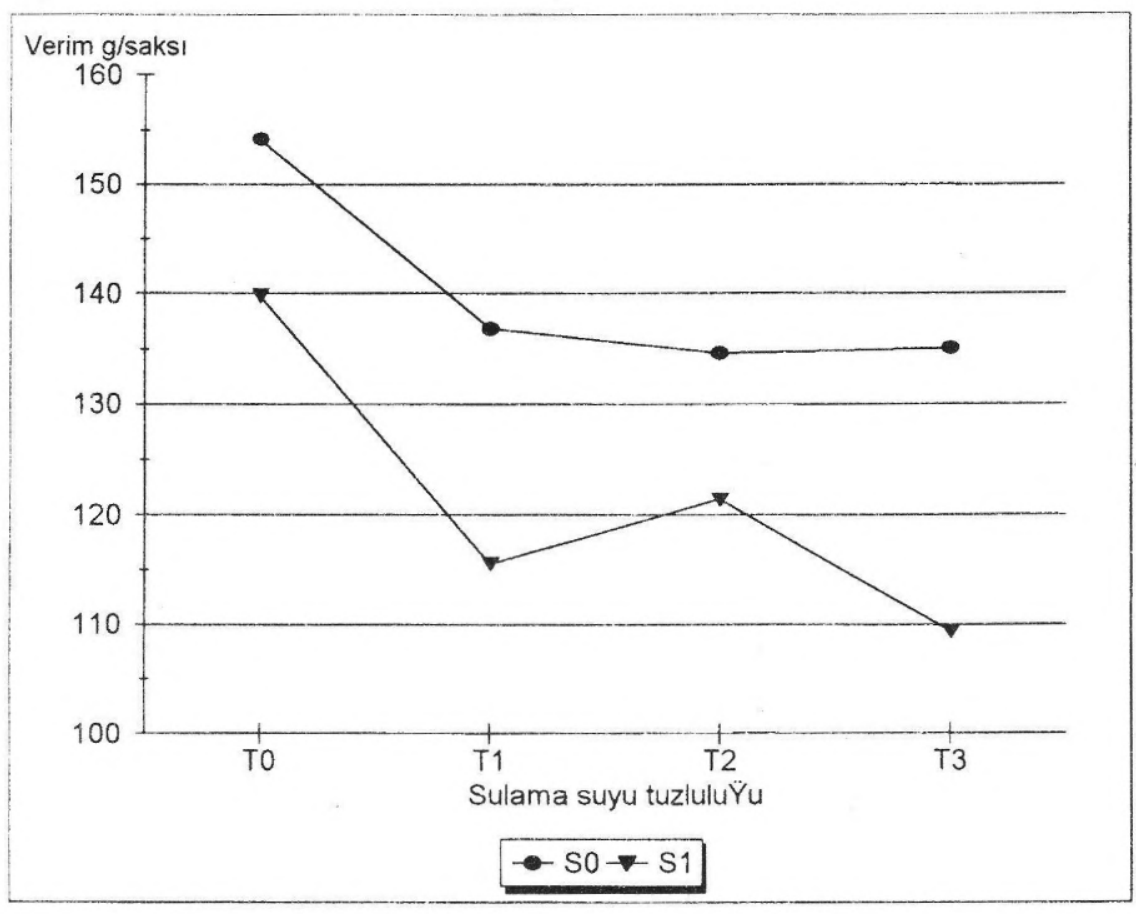

Şekil 1. Sulama suyu tuzłuluğu, sodyumluluğu ve verim ilişkisi

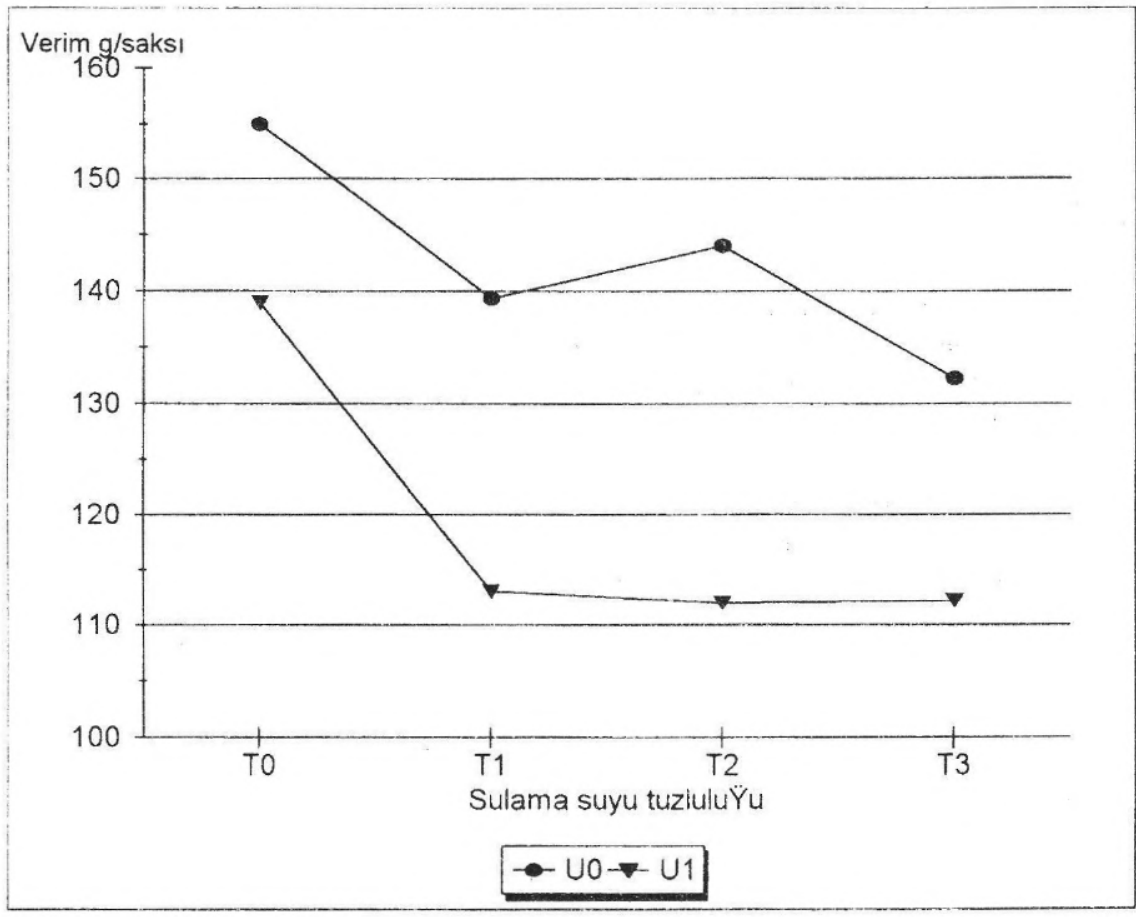

Şekil 2. Sulama suyu tuzluluğu, toprak nem içerikleri ve verim ilişkilsi 


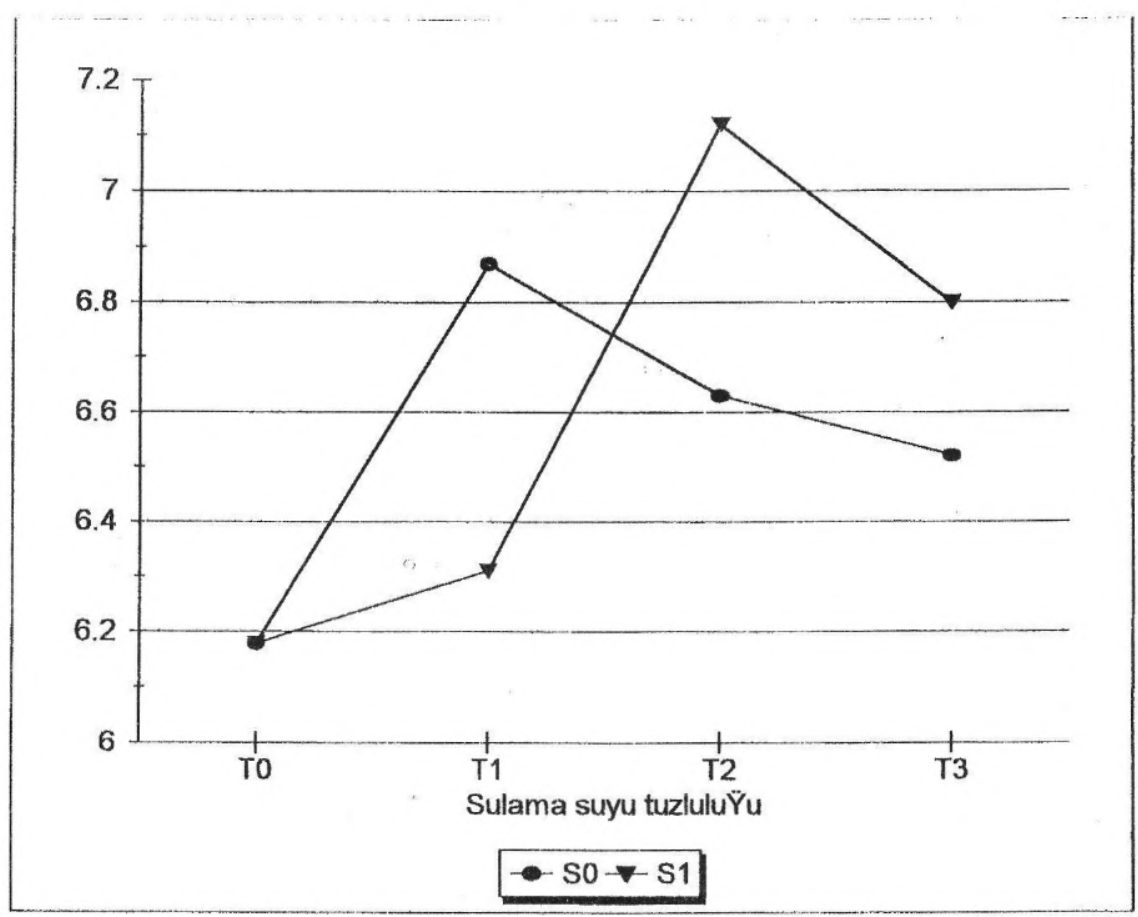

Şekil 3. Sulama suyu tuzluluğu, sodyumluluğu ve kuru madde miktarları ilişkisi

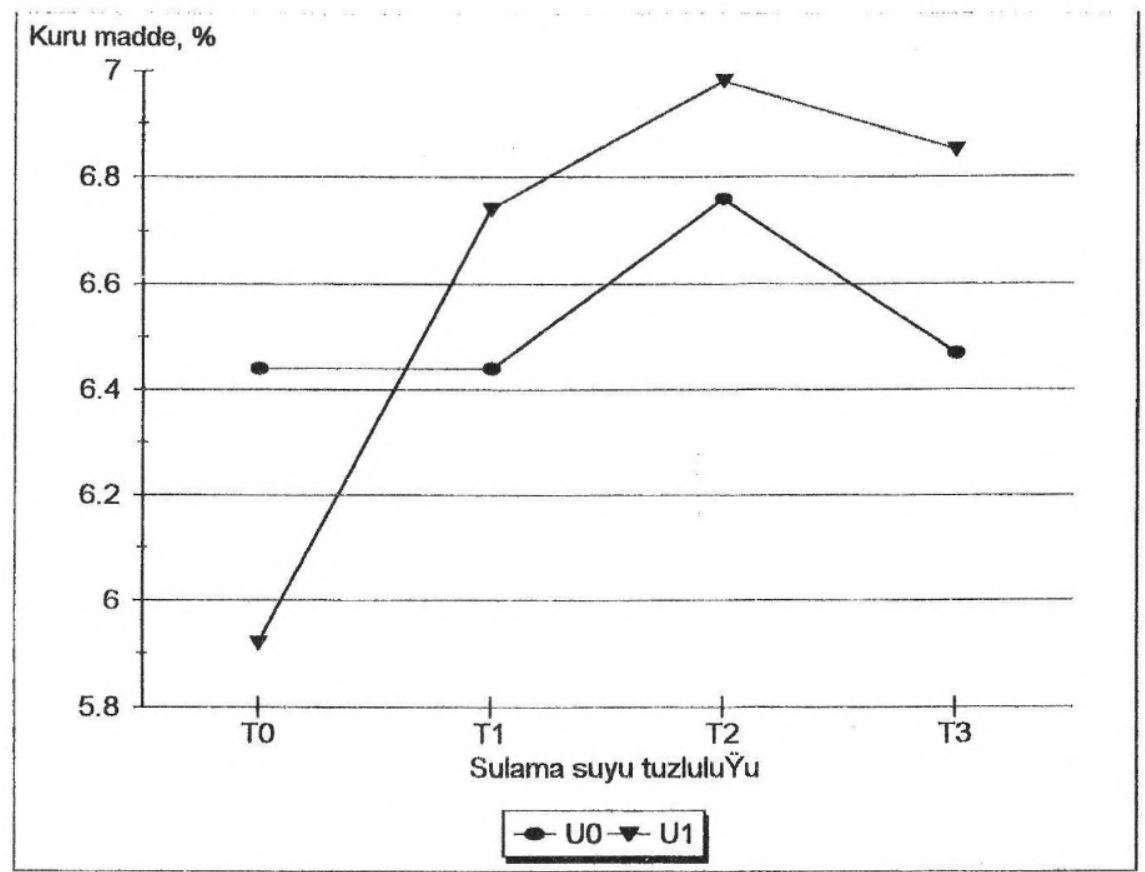

Şekil 4. Sulama suyu tuzluluğu toprak nem içeriği ve kuru madde miktarları ilişkisi 


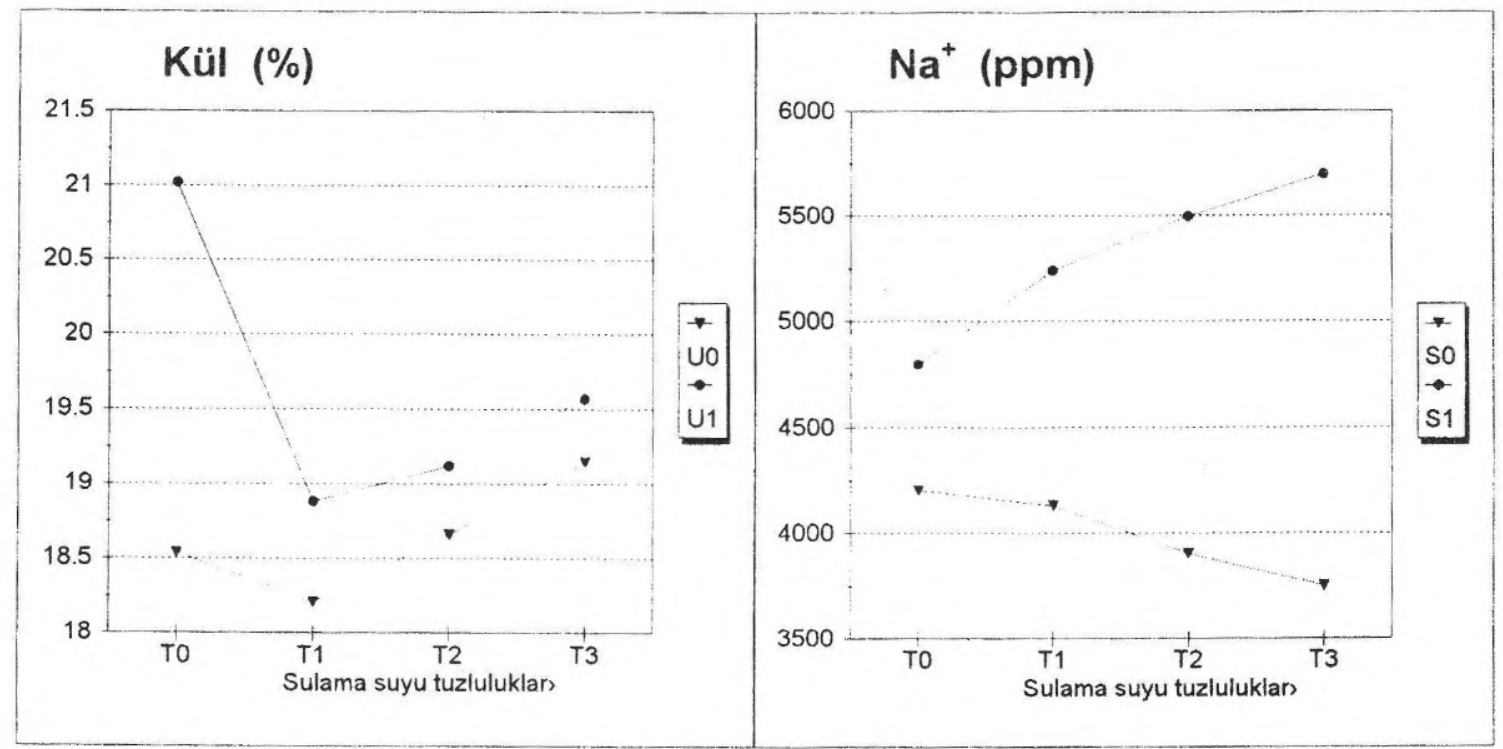

Şekil 5. Toplam kül içeriğinin nem içerikierne göre değişimi

Şekil 6. $\mathrm{Na}^{+}$içeriğinin SAR değerlerine göre değişimi

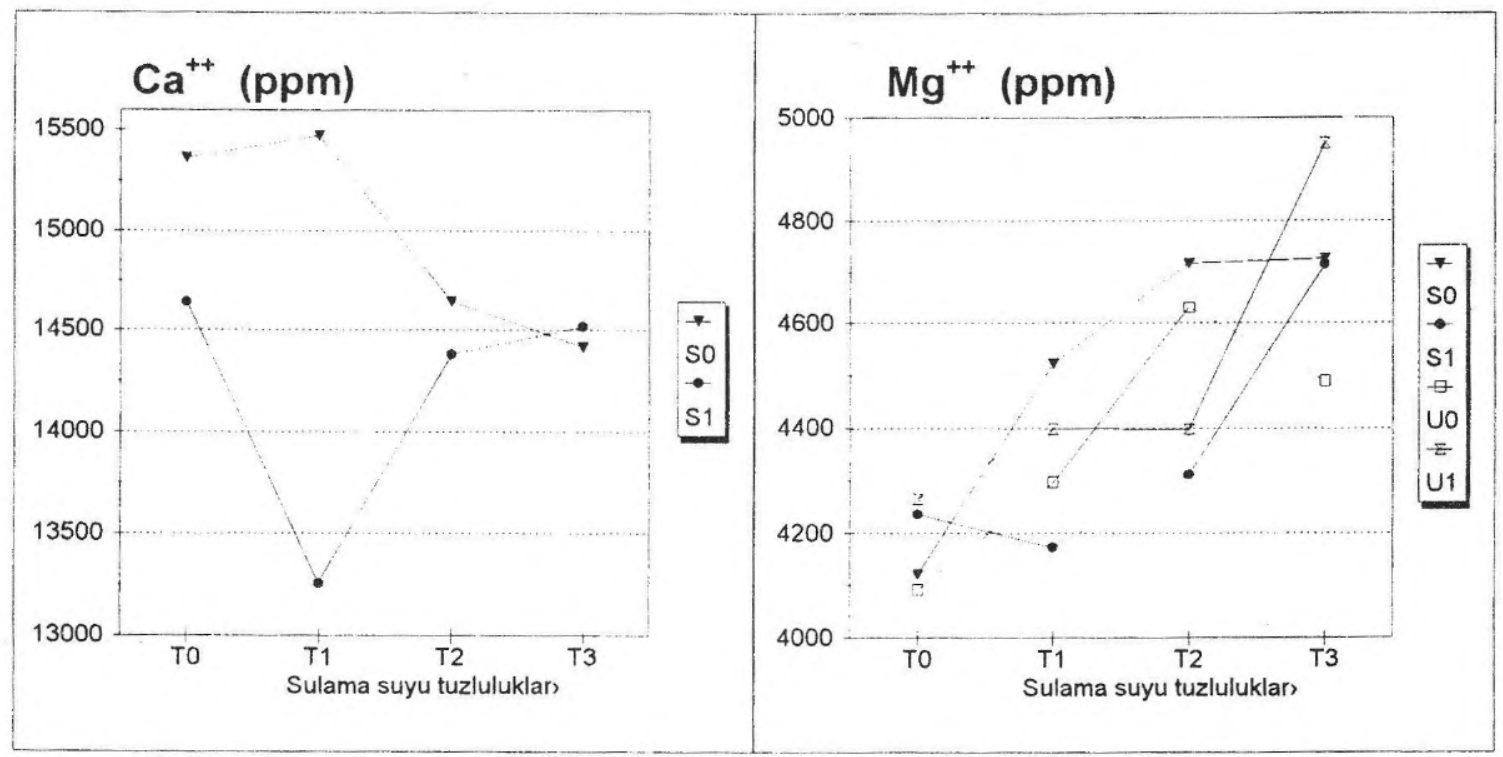

Şekil 7. Ca ${ }^{++}$içeriğinin SAR değerlerine göre değişimi

Şekil $8 . \mathrm{Mg}^{++}$içeriğinin SAR ve nem değerlerine göre değişimi 


\section{Sonuç}

Önemli bir besin kaynağı olan marul (Lactuca sativa cv. Tasna) bitkisi ile yapilan bu çalışmada; sulama suyu tuzluluğu ile sodyumluluğunun toprak nem içerikleri ile ilişkili olarak verim ve kalite üzerine olan etkileri araştırılmıştır. Marul tuza orta hassas bir bitkidir ve $E C_{i} \geq 2$ dS/m düzeyinde bitki yaş ağırlığında görülen azalma düzeyi $E C_{i}=6$ dS/m'ye kadar aynı oranda devam etmektedir. Sulama suyu SAR düzeyinin 5 'e yükselmesi de verimde \%13 lük bir azalmaya neden olmaktadır. Toprakta nem düzeyinin sık sulamalarla yüksek tutulması verim artışı sağlamaktadır. Önceden beklenenin aksine, toprak nem düzeyi ile tuzluluk etkileşimi istatistiksel olarak önemsiz bulunmuştur. Bu durum büyük olasılıkla $E C_{i}$ değerleri daha yüksek seçilmiş olsaydı, beklendiği gibi çıkabilecekti. Tuzluluğun etkisinden de görülebileceği gibi, ele alınan tuzluluk düzeylerinde 2 ila $6 \mathrm{dS} / \mathrm{m}$ aralığının verim üzerine olan etkileri benzer olmuştur.

Bitkide toplam kül, bir başka deyişle mineral madde içerikleri, sulama suyu tuzluluğunun artışı ile yükselmiştir. Çözelti ortamında bulunan mineral madde konsantrasyonunun değişmesi, bitkide alınarak biriktirilen mineral madde düzeylerini etkilemiştir. Potasyum çözelti ortamına verilmediği için bitkideki miktarları arasında da önemli bir farklılık görülmemiş, buna karşılık $\mathrm{Na}^{+}, \mathrm{Ca}^{++}$ve $\mathrm{Mg}^{++}$içerikleri, tuzluluk ve sodyumluluk konularına bağlı olarak önemli değişiklikler göstermiştir

\section{Kaynaklar}

Anonymous, 1954."Diagnosis and Improvement of Saline and Alcali Soils," U.S. Dept. of Agric. No.60, USA,

Anonymous, 1987."Tarım İstatistikleri Özeti," DIE Yaın No.1251, Ankara,

Ayers, A.D.; C.H.. Wadleigh and L. Bernstein, 1951. "Salt tolerance of six varieties of lettuce," Am.Soc for Hort. Sci., 57:237-242,
Ayers, R.S. and D.W. Westcot, 1989. "Water Quality for Agriculture," FAO Irrig. and Drain Paper No.29, 174s., Rome,.

Bouyoucos, G.S.1951."A recalibration of the hydrometer method for making mechanical analysis of soils," Agron. $\mathrm{J}_{-}$43:434-438.

Christiansen, J.E.; E.C. Olsen and L.S. 1977. Willardson, "Irrigation water quality evaluation," J. Irrig. and Drain Div., ASCE, 103:155-169,.

Dinar, $A . ;$ J. Letey and H.J. Vaux, 1986. "Optimal ratios of saline and non saline irrigation waters for crop production," Soil Sci. Soc. Am. J., Vol.50,

Dizdar, M.Y.,1981. "Toprak Etüd Raporu," TOPRAKSU Gn.Mid. Yayınları, Ankara,

Kacar, B., 1972. "Bitki ve Toprağın Kimyasal Analizleri: II.Bitki Analizleri," A.Ü. Ziraat Fak. Yayınları 453, 646s., Ankara,

Poonia, S.R. and R. PAL, 1979. "The effect of organic manuring and water transmission parameters and sodication of a sandy loam soil," Agric. Water Manage., 2:163-175,

Shannon, M.C.; J.D. Creight and J.H. Draper, 1983."Screening tests for salt tolerance in lettuce," J. Amer.Soc. Hort Sci. 88:,

Sonneveld, C. and J. van Den Eende, 1975."The effect of some salts on head weight and tipburn of lettuce and on fruit production and blossom-end root of tomatoes," Netherlands J. Agric. Sci. 23:191-201.

Yurtseven, E. ve B. Sönmez, 1996. "Sulama suyu tuzluluğunun domates verimine ve toprak tuzluluğuna etkisi," $D O G ̌ A$ Tr. J. of Agriculture and Forestry, 20:.

Yurtsever, N., 1984. "Deneysel İstatistik Metotlar," Köy Hizmetleri Gn.Md., Toprak ve Gübre Araşt. Enst. Md. Yayınları 121/56, Ankara, 